\title{
The paravalvular regurgitation enigma
}

\author{
Kevin L. Greason, MD
}

From the Division of Cardiovascular Surgery, Mayo Clinic, Rochester, Minn.

Disclosures: Author has nothing to disclose with regard to commercial support.

Received for publication June 23, 2016; accepted for publication June 25, 2016; available ahead of print July 27, 2016.

Address for reprints: Kevin L. Greason, MD, Division of Cardiovascular Surgery, Mayo Clinic, 200 First St, NW, Rochester, MN 55902 (E-mail: greason.kevin@mayo.edu).

J Thorac Cardiovasc Surg 2016;152:954-5

0022-5223/\$36.00

Copyright $\subset 2016$ by The American Association for Thoracic Surgery

http://dx.doi.org/10.1016/j.jtcvs.2016.07.013

It is a riddle wrapped in a mystery inside an enigma; but perhaps there is a key.

$$
\text { The Russian Enigma, October 1, } 1939
$$

Readers of the Journal will find interest in this article by Jones and colleagues ${ }^{1}$ about the prognostic significance of their 9-level clinical paravalvular regurgitation scale in predicting mortality after transcatheter aortic valve insertion. Although there is agreement that severe paravalvular regurgitation is associated with poor short- and long-term survival after transcatheter aortic valve insertion, such is not necessarily the case for the "riddle wrapped in a mystery inside an enigma" that makes up the moderate or less grades of paravalvular regurgitation. ${ }^{2-4}$

Possible reasons for the lack of agreement on the issue of paravalvular regurgitation are that there is no consensus on either the best imaging modality or method of quantification. The authors set the tone of the study by stating this about previously reported clinical paravalvular regurgitation scales, "Severity is traditionally judged based on a multi-parametric approach that combines information from multiple echocardiographic views, and contains some inherent subjectivity making broad, rigid characterizations difficult." The issue of subjectivity is nicely summed up by Toba Beta, who rightly stated, "Subjectivity measures nothing consistently."

In this study, the authors report their echocardiography experience in 237 patients operated with SAPIEN or SAPIEN XT (Edwards Lifesciences, Irvine, Calif) transfemoral transcatheter aortic valve insertion. The authors discriminated paravalvular regurgitation into nine grades and studied the impact of each grade on survival. They reported a step-wise increase in the adjusted hazard ratios for mortality based on progression of paravalvular regurgitation grade from none through mild-moderate (Table 2). Incredibly, the authors reported that even paravalvular regurgitation grade trivial-1+ had an adjusted hazard ratio for mortality of 4.4 (95\% confidence interval [CI], 1.2-27.7; $P=.02$ ) compared with paravalvular regurgitation grade "none."

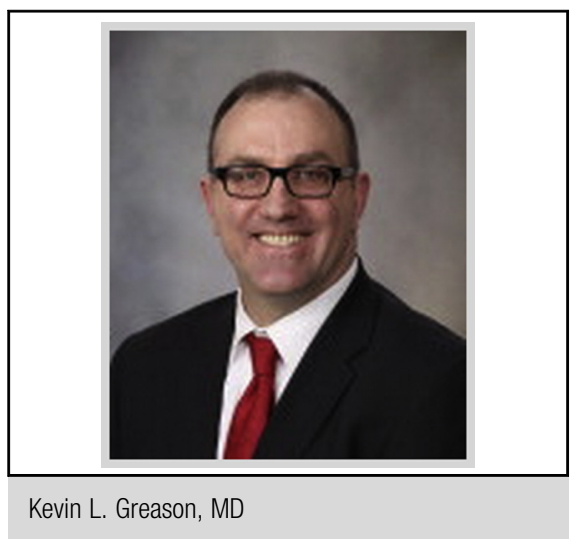

Central Message

Even paravalvular regurgitation grades less than mild are associated with reduced longterm survival after transcatheter aortic valve insertion.

See Article page 783 in the September issue.

The data and analysis in this study from the Cleveland Clinic group have demonstrated one thing for sure, whether you are a lumper or a splitter, paravalvular regurgitation is probably bad and a negative influence on survival after transcatheter aortic valve insertion. The perceived main strength of this study is the statistical discrimination of 9 grades of paravalvular regurgitation in only 237 patients. But what of the limitations of the large 95\% CIs (eg, 1.2-27.7), which probably result from the small sample size? Is the study at risk of a type I statistical error? What conclusions can then be drawn?

The final point to note is that, despite all the statistical stratagems, tables, and figures, the study still does not tell us why paravalvular regurgitation grade trivial-1+ has such a significantly negative influence on survival. What is the key? What is the pathophysiology that ties trivial paravalvular regurgitation to increased mortality? Could it be the paravalvular regurgitation is associated with hemolytic anemia or infection? What of calcification of the aortic annulus or valve and the risk of embolization, both intra-coronary and cerebral? The point is that correlation does not imply causation. And causation is the main question that needs to be answered.

For now, paravalvular regurgitation after transcatheter aortic valve insertion appears to remain an enigma. And not an inconsequential one either, as penalties of treatment with postdilation or oversizing are also not insignificant 
(eg, stroke and annular rupture). After reviewing this study, I remain a lumper rather than a splitter: paravalvular regurgitation grade none - good; anything other than that-not so good. What to do about the "not so good" remains unclear.

\section{References}

1. Jones BM, Tuzcu EM, Krishnaswamy A, Popovic Z, Mick S, Roselli EE, et al. Prognostic significance of mild aortic regurgitation in predicting mortality after transcatheter aortic valve replacement. J Thorac Cardiovasc Surg. 2016;152:783-90.
2. Leon MB, Smith CR, Mack MJ, Makkar RR, Svensson LG, Kodali SK, et al Transcatheter or surgical aortic-valve replacement in intermediate-risk patients. N Engl J Med. 2016;374:1609-20.

3. Kodali S, Pibarot P, Douglas PS, Williams M, Thourani V, Rihal CS, et al Paravalvular regurgitation after transcatheter aortic valve replacement with the Edwards sapien valve in the PARTNER trial: characterizing patients with impact on outcomes. Eur Heart J. 2015;36:449-56.

4. Popma JJ, Adams DH, Reardon MJ, Yakubov SJ, Kleiman NS, Heimansohn D, et al. Transcatheter aortic valve replacement using a self-expanding bioprosthesis in patients with severe aortic stenosis at extreme risk for surgery. $J$ Am Coll Cardiol. 2014;63:1972-81. 